\title{
AVALIAÇÃO DA GESTÃO NO ENSINO TÉCNICO PROFISSIONAL: IMPLICAÇÕES DA REFORMA DO ENSINO MÉDIO
}

\author{
EVALUACIÓN DE LA GESTIÓN DE LA ENSEÑANZA TÉCNICA PROFESIONAL: \\ IMPLICACIONES DE ESCUELA DE ENSEÑANZA SECUNDARIA
}

\section{MANAGEMENT ASSESSMENT IN VOCATIONAL EDUCATION: IMPLICATIONS OF HIGH SCHOOL REFORM}

\author{
Marcos Antonio Martins LIMA ${ }^{1}$ \\ Denize de Melo SILVA ${ }^{2}$ \\ Maria Lucijane Gomes de OLIVEIRA ${ }^{3}$ \\ Jaderson Cavalcante da SILVA ${ }^{4}$
}

RESUMO: A respectiva pesquisa objetiva avaliar a gestão das escolas profissionais da rede pública estadual localizadas em Fortaleza, no estado do Ceará. Para essa análise, consideraramse $(n=39)$ professores, no intuito de entender os efeitos da reforma do ensino médio para a organização e sistematização das ações pensadas para a avaliação e a gestão das escolas pesquisadas. A metodologia adotada centrou-se na estratégia metodológica quadripolar de Bruyne, Herman e Schoutheete (1977). O estudo inseriu-se na abordagem quantitativa do tipo descritiva e exploratória quanto ao seu objetivo geral. No tocante ao tratamento das análises oriundas dos dados quantitativos sobre a escala Likert de avaliação dos oito itens objetivos presentes no questionário semiestruturado para a pesquisa, foram adotadas as seguintes técnicas: o alfa de Cronbach $(\alpha)$, a Corrected Item-Total Correlation e a Análise Fatorial Exploratória.

PALAVRAS-CHAVE: Avaliação. Gestão. Ensino médio profissional. SAEB.

RESUMEN: La respectiva investigación objetiva evaluar la gestión de las escuelas profesionales de la red pública estadual umbicadas en Fortaleza, en el estado del Ceará. Para tal análisis, se consideran (n=39) profesores, con la meta de comprender los efectos de la reforma de la enseñanza média para la organización y sistematización de las acciones pensadas para la evaluación y la gestión de las escuelas pesquisadas. La metodología adoptada se centró en la estratégia metodológica de quadripolar de Bruyne Herman e Schoutheete (1977). El estúdio se inserto en el abordaje quantitativo del tipo descriptivo y exploratorio cuanto a su objetivo general. Sobre el tratamiento de los análisis oriundos de los

\footnotetext{
${ }^{1}$ Universidade Federal do Ceará (UFC), Fortaleza - CE - Brasil. Professor Associado do Departamento de Fundamentos da Educação. Pós-Doutorado em Gestão (UFRN). ORCID: http://orcid.org/0000-0001-5541-6220. E-mail: marcos.a.lima@terra.com.br

${ }^{2}$ Universidade Federal do Ceará (UFC), Fortaleza - CE - Brasil. Professora Assistente Nível I da Faculdade Cearense (FAC). Doutoranda em Educação. ORCID: http://orcid.org/5896-9505-3453-2512. E-mail: denisemellopedagoga@gmail.com

${ }^{3}$ Universidade Federal do Ceará (UFC), Fortaleza - CE - Brasil. Discente do Programa de Pós-graduação em Educação (PPGE). Membro do Grupo de Pesquisa em Avaliação e Gestão Educacional - GPAGE (UFC/CNPQ). ORCID: http://orcid.org/0000-0002-7136-7462. E-mail: luciijanne.oliveira@gmail.com

${ }^{4}$ Universidade Federal do Ceará (UFC), Fortaleza - CE - Brasil. Discente do Programa de Pós-graduação em Educação (PPGE). ORCID: http://orcid.org/0000-0002-4553-3340. E-mail: jaderson1987jcs@gmail.com
}

RPGE- Revista on line de Política e Gestão Educacional, Araraquara, v. 24, n. 2, p. 347-371, maio/ago., 2020. e-ISSN: 1519-9029. 
datos quantitativos sobre la escala Likert de evaluación de los ocho artículos objetivos presentes en el cuestionário semiestruturado para la investigación, fueron adoptados las siguientes técnicas: el alfa de Cronbach ( $\alpha)$, la Corrected Item-Total Correlation y Análise Fatorial Exploratória.

PALABRAS CLAVE: Evaluación. Gestión. Enseñanza media profesional. SAEB.

ABSTRACT: The respective research aims to evaluate the management of professional schools of the state public network located in Fortaleza, state of Ceará. For this analysis, $(n=39)$ teachers were considered in order to understand the effects of the reform of high school for the organization and systematization of the actions thought for the evaluation and management of the schools surveyed. The adopted methodology was centered around Bruyne, Herman and Schoutheete's (1977) quadripolar methodological strategy. The study was inserted in the quantitative approach of the descriptive and exploratory type regarding its general objective. Concerning the treatment of analysis from quantitative data on the Likert scale of the eight objective items present evaluated in the semi-structured questionnaire for the research, the following techniques were adopted: Cronbach's alpha $(\alpha)$, Corrected Item-Total Correlation and Exploratory Factor Analysis.

KEYWORDS: Evaluation. Management. Professional high school. SAEB.

\section{Introdução}

Observa-se que a gestão educacional atua como elemento norteador das práticas educativas, contexto no qual este artigo, sob a óptica da avaliação, objetivou avaliar a gestão escolar por meio dos desdobramentos da reforma do ensino médio e dos seus efeitos sobre a dinâmica das escolas técnico-profissionais.

Sabe-se que a avaliação institucional se constitui enquanto agente de melhorias na organização do espaço escolar. Dessa forma, questionamo-nos: qual a centralidade das políticas públicas pensadas para a educação básica? Será a avaliação um elemento de organização ou coerção dos comportamentos observados na escola? A gestão dispõe de autonomia no processo de organização das ações na escola?

Diante desses questionamentos, cabe considerar as políticas públicas e o modelo de gestão que regem a educação básica e a congruência com os projetos de educação voltados para a classe trabalhadora.

A epistemologia que rege as proposições deste estudo foi sedimentada sob o viés do materialismo histórico dialético. Dessa forma, entende-se que o prisma das condições materiais é um componente passível de observação e reflexão. O materialismo histórico dialético enquanto 
base de teoria científica da história embasa-se na evolução da sociedade e nas tentativas de explicação desse processo de desenvolvimento.

O tópico de discussão a seguir versará acerca da epistemologia de Karl Marx e das disposições iniciais centradas nas categorias trabalho e educação.

\section{Referencial teórico}

A discussão a ser apresentada versa sobre a epistemologia de Karl Marx condensada por meio das aproximações entre as categorias trabalho e educação. Busca-se refletir acerca dos fundamentos que interligam o trabalho e as relações sociais, culturais, políticas e históricas sedimentadas sob a óptica do materialismo histórico dialético.

\section{A epistemologia de Karl Marx: compreensões iniciais sobre o trabalho e educação}

A epistemologia de Karl Marx objetiva o entendimento das especificidades que regem o trabalho enquanto categoria fundante do ser social. Para se estabelecer as proposições de estudo com base no trabalho como princípio educativo, cabe compreender a historicidade material e estruturante da categoria trabalho como elemento basilar da respectiva proposição de estudo.

Nesse ínterim, segundo Engels (1876), o trabalho é a atividade fundante do ser social. À medida que o homem trabalhava, exercitava e experienciava relações complexas que exigiam de si estratégias, capacidade de adaptação e aprimoramento das suas próprias atividades, passando esses saberes de geração a geração. Os conhecimentos adquiridos durante esse processo de socialização funcionavam como estratégia para a disseminação dos conhecimentos adquiridos, bem como na garantia da própria existência diante das condições rudimentares de vida.

Para Carnoy (1987), o comportamento individual dos indivíduos é o produto de forças históricas que se ancoram nas condições materiais, cujas mudanças sociais alteram as relações entre os homens. Diante disso, conforme o pensamento do autor, "[...] Marx considerava as condições materiais de uma sociedade como base de sua estrutura social e da consciência humana" (CARNOY, 1987, p. 20).

O trabalho é, portanto, considerado a atividade fundante, ou seja, atividade de base material que torna possível o existir, condição para a vida humana. É por meio das necessidades de subsistência que o sujeito homem passou a modificar o seu ambiente, superando as 
intempéries relativas à sua rotina (ENGELS, 1876). Para o autor, a duração e a manutenção da vida humana estavam condicionadas à superação das adversidades e às estratégias adotadas para garantir esse objetivo, funcionando como importantes elementos para a formação e constituição do sujeito homem.

O trabalho como princípio educativo centra-se no protagonismo do homem enquanto sujeito social. O sujeito de ação torna-se autônomo nessa ação, reconhecendo-se enquanto sujeito de sua ação de base material. Para Titton (s/a), faz-se importante o reconhecimento da categoria trabalho como base de formação do homem social, tendo em vista que, ao entrarmos no debate acerca de uma polêmica fundamental como a que cerca o trabalho como princípio educativo, é imprescindível, em nossa avaliação, explicitar o ponto central que unifica os que estão envolvidos na polêmica, que é o reconhecimento do trabalho como categoria fundante do ser social. Assim, é necessário reafirmar seu significado, pelas implicações que daí decorrem em todo o processo de luta social e que envolvem, também, a produção do conhecimento (TITTON, s/a, p. 2).

O princípio educativo do trabalho caracteriza o trabalho como categoria fundante do ser social, reafirmando que o homem, quando produz suas condições básicas de vida, acaba produzindo a sua própria vida, ou seja, a produção do processo de saberes decorre da própria atividade do trabalho, criando, segundo o autor, um mundo humano. Essa capacidade de organização e sistematização é o que nos diferencia dos animais, pois estabelecemos relações maiores de aprofundamento sobre o mundo material das coisas.

O trabalho como princípio educativo, conforme Titton (s/a), surge como estratégia de base pedagógica, voltada à formação de cidadãos críticos-reflexivos sobre a utilização do trabalho como negação do homem, ou seja, relações de trabalho que contrariam as ideias de Engels e Marx. Para ele, essas propostas são voltadas e encaminhadas apenas para a geração de lucro e apropriação da riqueza por poucos, ocasionando relações de estranhamento e alienação do trabalho pelo trabalhador, ou seja, o trabalhador acaba não se apropriando do produto final do seu trabalho.

Titton (s/a) oferece uma reflexão sobre uma nova realidade, distinta do reducionismo empregado pelos moldes do sistema de produção, relacionando intimamente o trabalho, enquanto construção essencial ao homem, à formação ampla do indivíduo, proporcionando uma crítica reflexiva empregada na utilização do trabalho como atividade fundante do ser social. 


\section{A educação no ensino técnico-profissional}

A educação surge como uma necessidade à manutenção do sistema, ou seja, uma antecipação da fábrica, sendo a escola o ambiente ideal para inculcar nos trabalhadores disciplina e ordem, a fim de que reproduzam os conhecimentos gerados dentro da fábrica. Enguita (1989) faz relação entre a qualificação do trabalho e a desqualificação do trabalhador. A qualificação do trabalhador aumentou, porém, as suas expectativas em relação a melhores condições de trabalho e vida tornaram-se apenas ilusão diante das urgências que o sistema de produção não atende.

Enguita (1989) relata que os trabalhadores que aderem às péssimas condições de emprego estão em postos de trabalho denominados subempregos. Entretanto, os trabalhadores que não atendem a essa ordem crescente de qualificação e desqualificação acabam desempregados, por não aceitarem tais imposições. Kuenzer (1992) reafirma a concepção de escola de Enguita, mas leva em consideração que a escola pode ser sim o local em que a resistência se faça presente.

O lócus, portanto, da produção do conhecimento, é o conjunto das relações sociais; são inúmeras as formas de produção e distribuição do saber, resultantes do confronto cotidiano do homem com a natureza e com os seus pares, que lhe apresenta questões que o obrigam a desenvolver formas próprias de pensar e fazer, experimentando, discutindo, analisando, descobrindo (KUENZER, 1992, p. 27).

Assim, questiona-se: a escola insere-se em um movimento de reprodução, manutenção ou libertação da ordem vigente? Cabe o entendimento do contexto em que a escola está sedimentada, buscando ampliar, de forma contínua, as reflexões que permeiam essa construção.

No tópico de discussão a seguir, será discutida a dinâmica de intervenções e desafios no contexto do "novo ensino médio", os efeitos na legislação e para os sujeitos que compõem a dinâmica da modalidade educação profissional.

\section{Gestão no ensino técnico profissional}

Sabe-se que políticas públicas organizadas e sistematizadas para a escola centram-se como fios condutores para novas proposições e ações a serem realizadas no contexto educacional. Para Vieira (2015), a reflexão sobre a baixa qualidade fornecida aos discentes da educação básica apresentada massivamente nos resultados obtidos por meio das avaliações de larga escala, bem como nas produções e pesquisas veiculadas nos periódicos e eventos com tema central na educação é um elemento latente que necessita ser observado e contextualizado 
por meio de ações e políticas dialogadas que envolvam a escola e a participação da sociedade civil.

O caráter emergencial de ações de base material concreta foi percebido como ações deliberadas em forma de políticas públicas de caráter, aligeirado para a superação dos desafios da expansão, qualidade e permanência dos jovens no ensino médio.

Nas disposições legais vinculadas pelo Diário Oficial da União em 17 de fevereiro de 2017, verificaram-se mudanças substanciais relacionadas às práticas, conceitos, finalidades e funcionalidades do ensino médio, com base em modificações na Lei nº 9.394/1996.

Art. 36. O currículo do ensino médio será composto pela Base Nacional Comum Curricular e por itinerários formativos, que deverão ser organizados por meio da oferta de diferentes arranjos curriculares, conforme a relevância para o contexto local e a possibilidade dos sistemas de ensino, a saber: I linguagens e suas tecnologias; II - matemática e suas tecnologias; III - ciências da natureza e suas tecnologias; IV - ciências humanas e sociais aplicadas; V formação técnica e profissional (BRASIL, 2017).

Na observação da mudança do artigo no 36 , constatou-se o início de profundas mudanças curriculares a serem incorporadas por meio da Base Nacional Comum Curricular (BNCC). Nesse contexto, o ensino médio, por meio da respectiva legislação, deverá, pois, agregar os denominados itinerários formativos a serem organizados e ofertados pelas instituições escolares. No inciso V da lei supracitada, verificou-se a presença do eixo itinerário formação técnica e profissional, destacando-se como figura central da reforma no ensino médio apresentada pelo Governo Federal.

Diante desse contexto, faz-se necessário entender os pressupostos teóricos e conceitos presentes nas ações e deliberações realizadas por essas mudanças e quais os efeitos dessa reforma na gestão das escolas estaduais profissionais localizadas no município de FortalezaCE.

Para Newton Duarte e Betty Oliveira, em seu livro Socialização do saber escolar, essas ações configuram-se como iniciativas pobres de conceitos e base teórica e acabam centrandose em um aprendizado técnico e "capenga", do ponto de vista das aprendizagens requeridas nessa etapa do ensino. Para os autores, esse tipo de compreensão da educação acaba reduzindo as possibilidades de inserção social, pois compromete a aprendizagem dos conteúdos em detrimento de um caráter técnico de aprendizagem (DUARTE; OLIVEIRA, 1987).

A proposta pedagógica da escola antiga não se destinava à formação técnicoprofissional diante das necessidades imediatas; buscava-se uma formação mais voltada para as disciplinas tradicionais (BRASIL, 2017). 
A partir século XX, foi criada a escola de formação profissional em diferentes níveis e semelhante às escolas de formação propedêutica. A estrutura de educação profissional antiga baseava-se em técnicas de produção taylorista/fordista e posteriormente foi substituída por outro modelo de projeto pedagógico, determinado pelas mudanças ocorridas no mundo globalizado do trabalho e que, embora ainda hegemônico, vem surgindo como dominante, passando assim "[...] do antigo modelo taylorista-fordista para o modelo de produção flexível, conhecido como toyotista. Com o novo modelo, passou-se a exigir conhecimentos e habilidades mais complexas" (SOUZA; OKÇANA, 2013, p. 290).

De acordo com Cerqueira (2018), no período de 1856 a 1915, Taylor desenvolveu um conjunto de métodos para a produção industrial conhecida como taylorismo. De acordo com Taylor, o funcionário deveria apenas exercer sua função/tarefa em um menor tempo possível durante o processo produtivo, não havendo necessidade de conhecimento da forma como se chegava ao resultado final.

Ainda na visão do mesmo autor, Henry Ford (1863-1947), por sua vez, desenvolveu o sistema de organização do trabalho industrial denominado fordismo. A principal característica do fordismo foi a introdução das linhas de montagem, nas quais cada operário ficava em um determinado local realizando uma tarefa específica, enquanto o automóvel (produto fabricado) se deslocava pelo interior da fábrica em uma espécie de esteira. Com isso, as máquinas ditavam o ritmo do trabalho.

Nos tempos atuais, a coletividade proporciona novas relações entre trabalho, ciência e cultura e, a partir desse construto histórico, surge um novo modelo educativo, ou seja, um novo projeto pedagógico. Por esse motivo, a sociedade visa a transformar a formação de "[...] intelectuais/trabalhadores, os cidadãos/produtores para atender às novas demandas postas pela globalização da economia e pela reestruturação produtiva" (SOUZA; OKÇANA, 2013, p. 290).

De acordo Souza e Okçana (2013), a educação baseada na formação por competências instiga a resolução de problemas, pois torna desafiante para o aluno trabalhar com os conhecimentos adquiridos e aguça a criatividade na busca de novas tecnologias. O conteúdo aplicado é o meio, ou seja, o fundamento e não o mero repasse de saberes para cumprimento de um conteúdo programático. O professor é mediador do processo de aprendizagem, tornando o aluno um ser autônomo e capaz de tomar decisões.

Ainda de acordo os autores acima citados, observa-se que as demandas do mundo do trabalho se tornam cada vez mais mutantes, complexas e competidoras. Assim, a educação profissional aponta possibilidades para a construção de práticas inovadoras, mas condizentes com os avanços tecnológicos e as novas formas de produção e de relações sociais. 
Em consonância com a Lei de Diretrizes e Bases da Educação Profissional (LDB), a Lei $n^{\circ}$ 9.394/1996, em seu artigo 39, afirma-se que a educação profissional integra as diferentes formas de educação, o trabalho, a ciência e a tecnologia e tem o objetivo de conduzir ao desenvolvimento de aptidões para a vida produtiva. As instituições de educação profissional devem elaborar um trabalho direcionado ao preparo de pessoas que tenham aprendido a construir autonomamente novas competências para o trabalho e sejam capazes de articular e incorporar as diferentes áreas do saber (SOUZA; OKÇANA, 2013, p. 297).

Souza e Okçana (2013 p. 296) afirmam que:

O desenvolvimento das competências surge para atender as exigências específicas do mercado e da sociedade atual. É necessário que o profissional de hoje desenvolva competências técnicas e humanas, visando crescimento, aperfeiçoamento e eficácia nos resultados, tendo como premissa que o ser humano tem um poderoso potencial, e que acaba sendo o diferencial competitivo das organizações.

Corroborando Souza e Okçana (2013), observa-se que as novas reinvindicações competitivas que marcam o mercado globalizado e trazem o avanço de novas tecnologias se fazem presentes no cotidiano do trabalhador, evidenciando a crescente exigência do perfil profissional adequado à promoção de situações de aprendizagem que colaborem não só para o enfrentamento das exigências implícitas, mas também para uma atitude transformadora.

\section{Sistema Nacional de Avaliação da Educação Básica}

Sabe-se que o Sistema Nacional de Avaliação da Educação Básica direciona-se para o monitoramento e acompanhamento das ações que são estabelecidas no contexto educativo. Dessa forma, verifica-se, pois, o nivelamento das redes e sistemas de ensino na promoção de uma educação pública de qualidade. Conforme Bauer (2010), as avaliações externas articulamse para a melhoria da qualidade dos sistemas educacionais, pois se atrelam ao rendimento dos estudantes, e das variáveis contextuais presentes nas redes e sistemas de ensino.

As avaliações externas configuram-se como elemento de equidade para o delineamento da educação pública de qualidade. Para tanto, considerando a vigente LDB, no título IV, denominado "Da organização da Educação Nacional”, no artigo $8^{\circ}$, estabeleceu-se que a União, os Estados, o Distrito Federal e os Municípios possam compartilhar ações coletivas em regime de colaboração para os respectivos sistemas de ensino. Dessa forma, em consonância com a respectiva lei: 
[...] § $1^{\circ}$ Caberá a União, a coordenação da política nacional de educação, articulando os níveis e os sistemas e exercendo função normativa, redistributiva e supletiva em relação às demais instâncias educacionais. $\S 2^{\circ}$ Os sistemas de ensino terão liberdade de organização nos termos dessa lei (BRASIL, 2017).

Para Santos, Gimenes e Mariano (2013), as avaliações externas atrelam-se ao contexto mundial de articulação de ações para a promoção da qualidade educacional. A partir de 1990, houve, pois, a materialização quantitativa dos dados decorrentes dos indicadores acerca do processo de ensino e aprendizagem.

Em nosso país, o Ministério da Educação (MEC), em articulação com as Secretarias Estaduais de Educação, implantou o Sistema de Avaliação da Educação Básica (SAEB). A justificativa para a implementação desse sistema está associada à defesa da avaliação como possibilidade de fornecer informações sobre os processos educacionais, seja na esfera municipal ou estadual, com o intuito de direcionar o processo de tomadas de decisões em relação às políticas públicas, ao desempenho acadêmico dos alunos e à qualidade do sistema escolar como um todo (SANTOS; GIMENES; MARIANO, 2013, p. 40).

A respectiva estruturação do SAEB direciona-se no artigo 24, quando diz que:

[...] a verificação do rendimento escolar observará critérios, dentre eles podemos destacar: a) avaliação contínua e cumulativa do desempenho do aluno, com prevalência dos aspectos qualitativos sobre os quantitativos e dos resultados ao longo do período sobre os de eventuais provas finais (BRASIL, 2017).

Nessa perspectiva, Bonamino e Franco (1999) salientam a importância dos organismos internacionais para a proposição de políticas públicas a serem regulamentadas pelos países em desenvolvimento. Essa análise está presente nas políticas educacionais sobre os currículos escolares e sobre a gestão dos sistemas e redes de ensino. Assim, a presença dos organismos internacionais sobre a gerência da educação estabelece diretrizes específicas para a promoção de ações e políticas públicas voltadas para a área.

Assim, para Pinto e Viana (2019), as avaliações externas ligadas ao escopo e à dinâmica educacional são tecidas e financiadas pelos organismos internacionais. Desde 1990, o Banco Mundial (BM) articula diretrizes para a promoção de mudanças à educação brasileira nas esferas municipal, estadual e federal. Nessa perspectiva, a avaliação externa, por meio da consolidação do Sistema Nacional de Avaliação da Educação Básica, constituiu-se enquanto desdobramento das ações do BM na educação nacional.

Em virtude do Decreto $\mathrm{n}^{\circ}$ 9.432, de 29 de junho de 2018, estabeleceu-se no formato de Lei $\mathrm{n}^{\circ}$ 13.005, datada de 2014, a materialização concreta da necessidade de articulação por meio 
do caráter legislativo, com a congruência entre a política e as avaliações externas. Partindo da premissa de acompanhamento e monitoramento das aprendizagens desenvolvidas no interior das instituições de ensino, necessita-se, pois, de investigação continuada. Dessa forma, cabe asseverar que o respectivo Decreto compreende a ampliação e valorização do SAEB como instrumento ancorado na Política Nacional de Avaliação e Exames da Educação Básica, a saber:

Art. $3^{\circ}$ São princípios da Política Nacional de Avaliação e Exames da Educação Básica: I - igualdade de condições para o acesso e a permanência do estudante na escola; II - garantia do padrão de qualidade; e III - garantia do direito à educação e à aprendizagem ao longo da vida. Art. $4^{\circ}$ Integram a Política Nacional de Avaliação e Exames da Educação Básica: I - o Sistema de Avaliação da Educação Básica - Saeb; II - o Exame Nacional para Certificação de Competências de Jovens e Adultos - Enceja; e III - o Exame Nacional do Ensino Médio - Enem (BRASIL, 2017).

Diante desse contexto, a avaliação externa, em consonância com o modelo de gestão e avaliação, direciona-se enquanto instrumento das ações direcionadas para a aprovação da Base Nacional Comum Curricular e de um nível de ensino, nesse caso, o Ensino Médio, intrinsecamente relacionado às disposições internacionais adotadas pelos organismos internacionais para a organização da educação nos países da América Latina, incluindo o Brasil.

Dessa forma, a seguir, será apresentada a estruturação sedimentada para a respectiva pesquisa, no intento de entender os efeitos e ações realizadas nas escolas públicas da rede estadual localizadas no município de Fortaleza-CE, por meio do modelo de gestão ancorada nessas escolas e os direcionamentos obtidos a partir das orientações estabelecidas por intermédio do SAEB para o Ensino Médio Profissional Tecnológico.

\section{Metodologia da pesquisa}

A respectiva pesquisa enquadra-se na abordagem quadripolar. Desse modo, este estudo foi desenvolvido em quatro polos de investigação que versam acerca da compreensão metodológica sedimentada por Bruyne, Herman e Schoutheete (1977). Para tanto, sob a óptica do materialismo histórico dialético de Karl Marx (1818-1883), procurou-se realizar uma articulação crítica da educação profissional enquanto modalidade de ensino e os efeitos dessa dinâmica na esfera estadual de ensino público localizada em Fortaleza-CE. Assim, parte-se das inquietudes deste estudo: quais são os efeitos ocasionados pelo fortalecimento das avaliações externas nas instituições estaduais de ensino localizadas em Fortaleza, Ceará? Qual o papel da gestão escolar nessa dinâmica educativa? Quais são as práticas de gestão que corroboram ou não para o alcance dos índices tecidos pelo Sistema Nacional de Avaliação da Educação Básica? 
Dessa forma, elegeram-se os resultados obtidos pelas escolas denominas EEEPs (Escolas Estaduais de Ensino Profissionalizante) localizadas no município de Fortaleza, Ceará, para o recorte metodológico adotado na pesquisa para o Ensino Médio (EM) das respectivas instituições enquadradas no escopo supracitado.

A respectiva pesquisa enquadra-se ainda na abordagem quantitativa estruturada por meio da estatística descritiva e inferencial. Para isso, adotou-se o software SPSS (Statistical Package Social Sciences) versão 21.0 para o Windows, condensado a partir da análise de (n=39) sujeitos professores oriundos das escolas públicas estaduais localizadas em Fortaleza, no estado do Ceará. Assim, a amostra configurou-se por meio da disponibilidade dos sujeitos da pesquisa.

Realizou-se a estruturação de um Termo de Consentimento Livre Esclarecido, com o objetivo de solicitar o envolvimento e a participação dos docentes no estudo. Contudo, mediante as demandas apresentadas pelas escolas, apenas $(n=39)$ sujeitos optaram por participar da pesquisa. De acordo com a Secretaria de Educação (2019), as Escolas Estaduais de Educação Profissional do Ceará, em 2008, tiveram 25 unidades inauguradas em seu primeiro ano de funcionamento. Atualmente, o estado do Ceará possui mais de 119 instituições inseridas na modalidade de Educação Profissional.

A pesquisa de campo centrou-se no município de Fortaleza, no Estado do Ceará, em dez unidades escolares correspondentes a: Regional I, Regional II, Regional III, Regional IV e Regional V. Contudo, apenas $(\mathrm{n}=39)$ sujeitos professores decidiram participar do respectivo estudo.

O instrumento de coleta de dados aplicado na pesquisa corresponde a um questionário semiestruturado e foi construído com base em duas seções. A seção denominada A faz menção ao perfil dos sujeitos respondentes da pesquisa, incluindo assertivas que versam sobre gênero, faixa etária, função da escola, estado civil, renda familiar, tempo na instituição e a escolaridade.

A segunda seção do questionário, denominada $\mathrm{B}$, foi estruturada com base nos indicadores do SAEB, ou seja, oito itens objetivos medidos em uma escala Likert de avaliação. O grau de variação foi composto por cinco categorias de medidas, a saber: 0 - Não sei responder; 1 - Discordo totalmente; 2 - Discordo parcialmente; 3 - Concordo parcialmente; e 4 - Concordo plenamente. Desse modo, a elaboração dos itens desse instrumento está fundamentada, sobretudo, segundo as concepções de Severino (2016) e vinculada aos fatores de desempenho dos estudantes e das práticas e métodos de gestão evidenciados no modelo das instituições pesquisadas.

Quanto ao tratamento das análises dos dados quantitativos sobre a escala Likert de avaliação dos oito itens objetivos, optou-se por utilizar, sobretudo, como técnicas de análise estatísticas, o alfa 
de Cronbach $(\alpha)$, as Corrected Item-Total Correlation e a Análise Fatorial Exploratória (AFE), a fim de avaliar sua qualidade, refinamento, organização, emissão de juízo de valor e validação dos dados. Para isso, aplicamos o software Statistical Package for the Social Sciences (SPSS), versão 20.0 para Windows, tomando como referências teóricas as concepções de Pontes Júnior (2014) e de Field (2009).

Para Bruyne et al., (1977), a pesquisa conduz o olhar contextual acerca dos desafios na organização da escola pública, tecendo reflexões acerca dos indicadores que circundam a modalidade estudada. Corroborando, Minayo, Deslandes, Cruz Neto e Gomes (1994, p. 13) estabelecem que: "O objeto das ciências sociais é histórico. Isto significa que as sociedades humanas existem num determinado espaço cuja formação social e configuração são específicas".

\section{Análise e discussão dos resultados}

O presente artigo possui finalidade básica, caráter exploratório e abordagem quantitativa, segundo as concepções encontradas em Marconi e Lakatos (2015). Nesse sentido, esta pesquisa objetivou avaliar a gestão por meio de fatores associados ao Sistema Nacional de Avaliação da Educação Básica, sendo que a amostra foi composta por $(n=39)$ respondentes. Assim, os resultados da análise quantitativa foram evidenciados por meio de gráficos, tabelas, figuras e quadros, buscando uma melhor inferência e interpretação da realidade, bem como, para indicar as recomendações tecidas por meio da realização da respectiva pesquisa. As análises dos dados estão organizadas em duas seções, tais como: perfil do respondente; avaliação e gestão dos fatores associados ao desempenho dos estudantes vinculados à gestão e à avaliação realizada nas escolas por intermédio da escola construída.

\section{Perfil do respondente}

O perfil dos respondentes que compõem a amostra totaliza $39(\mathrm{n}=39)$ professores respondentes, sendo esses analisados em gênero; faixa etária; estado civil; renda familiar e escolaridade, como destacaremos a seguir.

No que diz respeito ao gênero dos respondentes, percebeu-se que 59\% ( $n=23)$ correspondem ao gênero masculino e 35,9\% (n=14) ao gênero feminino; e, ainda, 5,1\% (n=2) não responderam, como mostra o gráfico 1, apresentado a seguir. Em relação à faixa etária, verificou- 
se que $87,2 \%(n=34)$ possuem idade de 25 anos ou mais, enquanto $12,8 \%(n=5)$ possuem idade entre 20 a 24 anos de idade, conforme mostra o gráfico 2.

\section{Gráfico 1 - Gênero}

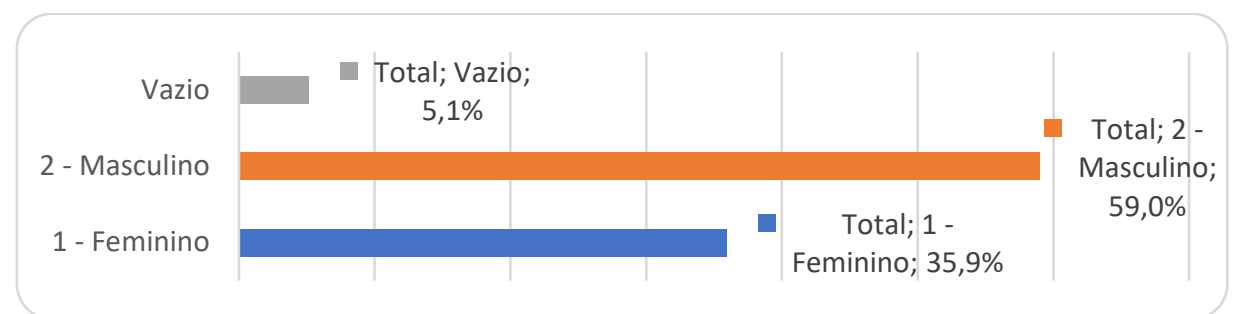

Fonte: Elaboração própria (2019).

Gráfico 2 - Faixa etária

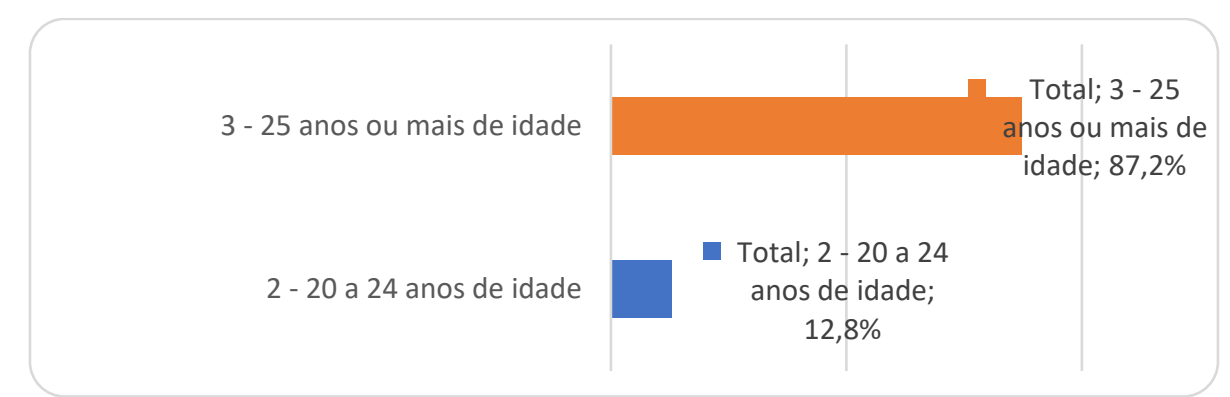

Fonte: Elaboração própria (2019).

No tocante ao estado civil dos respondentes, notou-se que 51,3\% ( $\mathrm{n}=20)$ são solteiros; 28,2\% (n=11) são casados; 12,8\% (n=5) são separados; e 7,7\% (n=3) destacaram outro tipo, conforme mostra o gráfico 3. Em relação à renda familiar dos respondentes, verificou-se que 46,2\% (n=18) recebem até três salários mínimos; 20,5\% (n=8) recebem até quatro salários mínimos; 30,8\% (n=12) recebem até cinco salários mínimos ou mais; e 2,6\% (n=1) não souberam responder, como mostra o gráfico 4.

\section{Gráfico 3 - Estado civil}

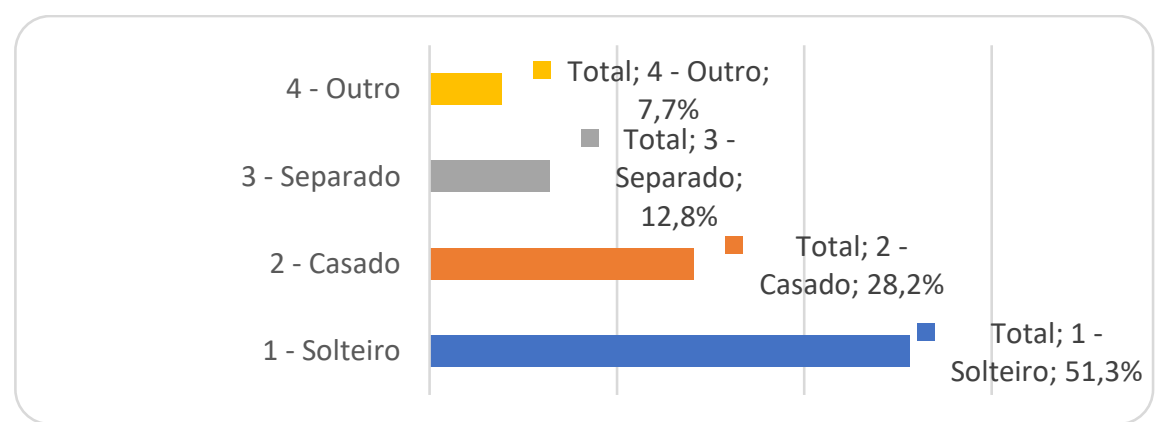

Fonte: Elaboração própria (2019). 
Gráfico 4 - Renda familiar

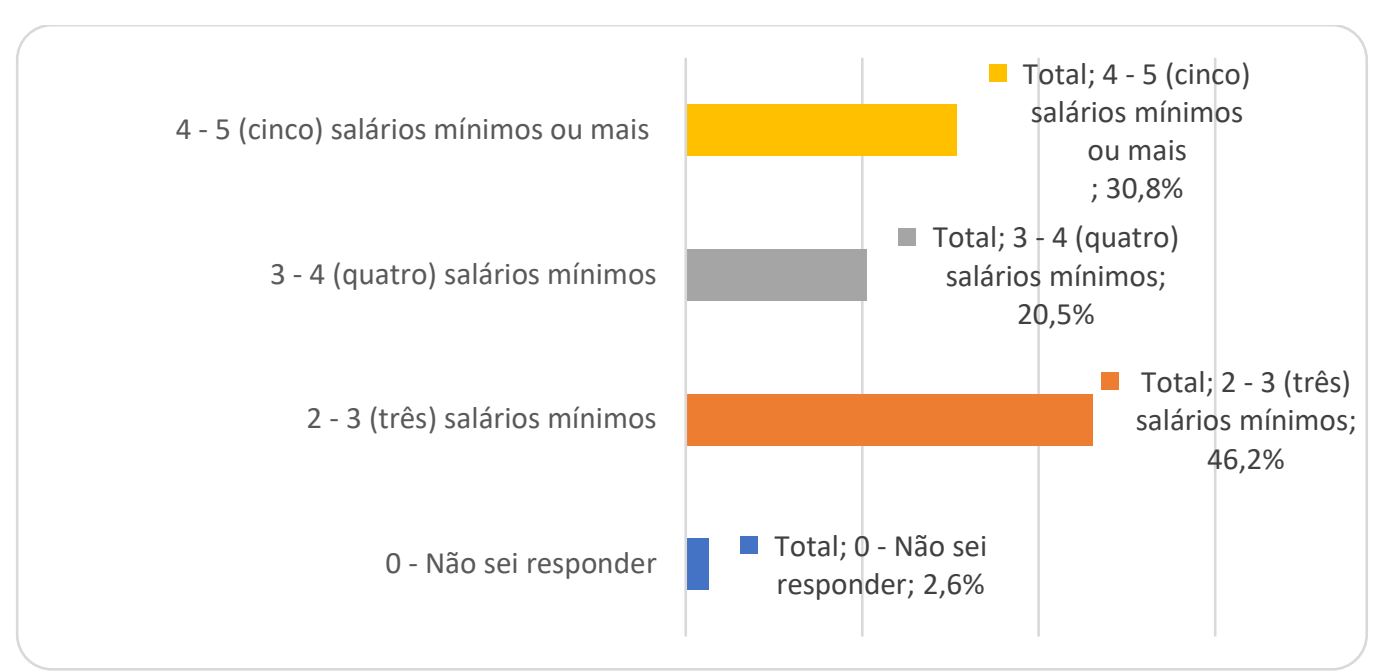

Fonte: Elaboração própria (2019).

No que tange à escolaridade dos respondentes, observou-se que 74,4\% (n=29) possuem pós-graduação, enquanto $25,6 \%(n=10)$ possuem graduação, conforme mostra o gráfico 5. Já quanto à função que exercem na escola, verificou-se que 2,6\% $(n=1)$ é a porcentagem para diretor; 7,7\% (n=3) pertencem ao núcleo gestor; e 89,7\% (n=35) são docentes, como retrata o gráfico 6.

Gráfico 5 - Escolaridade

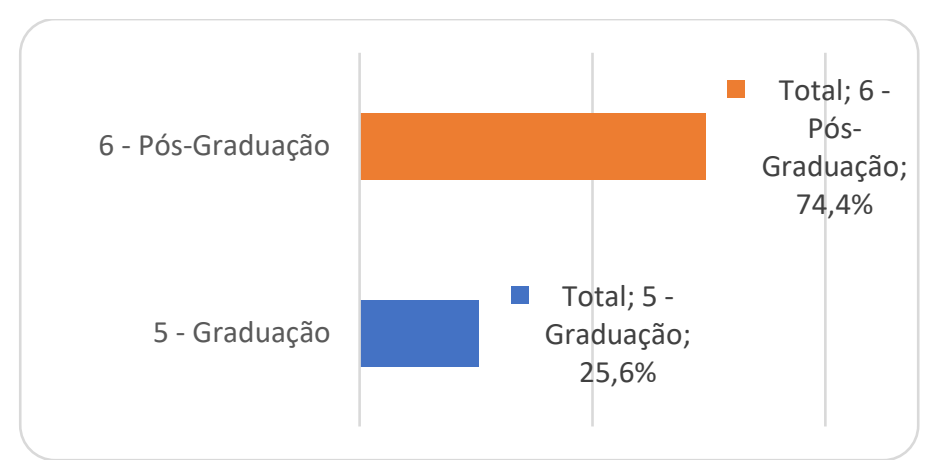

Fonte: Elaboração própria (2019).

Gráfico 6 - Função na escola

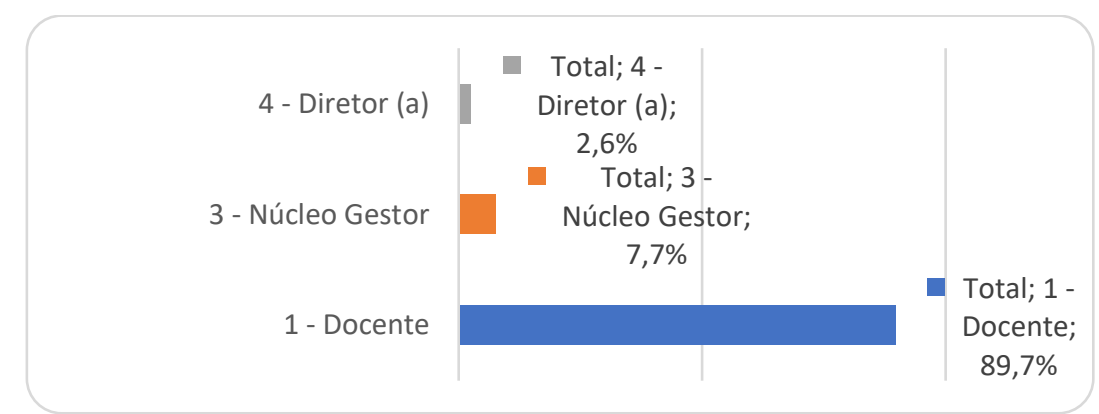

Fonte: Elaboração própria (2019).

RPGE- Revista on line de Política e Gestão Educacional, Araraquara, v. 24, n. 2, p. 347-371, maio/ago., 2020. e-ISSN: 1519-9029. 
Portanto, a amostra formada dos $(\mathrm{n}=39)$ respondentes apresenta como as suas maiores características: o gênero é masculino (59\%); a idade varia de 25 anos ou mais (87,2\%); o estado civil é solteiro (51,3\%); a renda familiar circunscreve até três salários mínimos (46,2\%); o nível de escolaridade é de pós-graduação $(74,4 \%)$; e a função que exerce na escola é de docente $(89,7 \%)$. Dessa forma, a seguir serão condensados os fatores relativos ao desempenho do Núcleo Gestor por meio do modelo de gestão empregado nas respectivas escolas profissionais da rede pública estadual localizadas no município de Fortaleza, Ceará.

\section{Percepções dos docentes relacionadas ao modelo de gestão empregada nas EEEPS}

A escala de avaliação com itens medidos em uma escala Likert apresenta uma totalidade de oito itens. Logo, constatou-se uma qualidade boa e satisfatória em sua composição e formulação, pois o alfa de Cronbach $(\alpha)$ é igual a 0,79 e as Corrected Item-Total Correlation passaram a variar entre $[0,30 ; 0,69]$, como mostra o quadro 1.

Quadro 1 - Corrected Item-Total Correlation dos oito itens

\begin{tabular}{|c|c|}
\hline \multicolumn{2}{|l|}{ Item-Total Statistics } \\
\hline & $\begin{array}{l}\text { Corrected } \\
\text { Item-Total } \\
\text { Correlation }\end{array}$ \\
\hline $\begin{array}{l}\text { Q.1 No tocante à liderança: gestor e educadores desenvolvem visão, missão, } \\
\text { valores e ética relacionados aos educandos. }\end{array}$ & 0,53 \\
\hline $\begin{array}{l}\text { Q.2 O gestor compromete-se em assegurar a implementação dos planos de ação } \\
\text { através dos seus respectivos programas de ação. }\end{array}$ & 0,30 \\
\hline $\begin{array}{l}\text { Q.3 O núcleo gestor desenvolve parcerias e diálogos entre professores, alunos e } \\
\text { comunidade escolar. }\end{array}$ & 0,69 \\
\hline $\begin{array}{l}\text { Q.4 O núcleo gestor verifica as demandas a partir das relações vivenciadas na } \\
\text { escola, promovendo resoluções por meio de ações proativas. }\end{array}$ & 0,64 \\
\hline $\begin{array}{l}\text { Q.5 A equipe gestora auxilia no trabalho coletivo, na disciplina e no } \\
\text { estabelecimento de respeito entre os sujeitos que integram a escola. }\end{array}$ & 0,62 \\
\hline Q.6 A formação ofertada aos docentes constitui-se de forma atenta e continuada. & 0,46 \\
\hline $\begin{array}{l}\text { Q.7 Na dinâmica apresentada na escola, observa-se o envolvimento entre o } \\
\text { núcleo gestor e a comunidade escolar }\end{array}$ & 0,41 \\
\hline $\begin{array}{l}\text { Q.8 As estratégias de comunição adotadas na escola são eficazes para a } \\
\text { integração entre a gestão, professores, discentes e comunidade escolar. }\end{array}$ & 0,48 \\
\hline
\end{tabular}

Fonte: Elaboração própria (2019) a partir do SPSS (20.0).

Após isso, decidiu-se aplicar a técnica multivariada denominada Análise Fatorial Exploratória (AFE), a partir dos oito itens que foram avaliados com qualidade boa, pois a formulação desses itens apresenta uma multiplicidade de informações. Nesse sentido, a fim de emitir um juízo de valor consistente sobre a matriz de dados, avaliou-se que as três etapas 
denominadas de adequação da amostra, extração de fatores e rotação dos fatores foram atendidas satisfatoriamente, como orienta a concepção de Pontes Júnior (2014) que sintetiza os pressupostos da AFE na figura 1.

Figura 1 - Pressupostos da AFE

\begin{tabular}{|c|c|c|c|}
\hline Etapa & Técnica & Objetivo & Valor adequados \\
\hline \multirow[t]{3}{*}{$\begin{array}{l}1^{\text {a }} \text { adequação da } \\
\text { amostra }\end{array}$} & Correlação de Pearson & $\begin{array}{l}\text { Obter o nivel de relação entre os } \\
\text { itens com algum fator }\end{array}$ & $\begin{array}{l}0 \text { à } 0,29 \text { - fraca relação } \\
0,3 \text { à } 0,69-\text { moderada } \\
\text { relação } \\
\begin{array}{l}\text { Acima de } 0,7 \quad-\text { forte } \\
\text { relação }\end{array}\end{array}$ \\
\hline & $\begin{array}{l}\text { Kaiser-Meyer-Olklin } \\
\text { (KMO) }\end{array}$ & $\begin{array}{l}\text { Identificar a adequação do tamanho } \\
\text { da amostra para o conjunto de itens }\end{array}$ & $\begin{array}{l}0,6 \text { a } 0,69-\text { aceitável } \\
0,7 \text { a } 0,79-\text { bom } \\
0,8 \text { a } 0,89-\text { ótimo } \\
\text { Acima de } 0,9-\text { excelente }\end{array}$ \\
\hline & $\begin{array}{l}\text { Teste de esfericidade } \\
\text { de Bartlett (BTS) }\end{array}$ & $\begin{array}{l}\text { Testa a hipótese de que foi gerada } \\
\text { uma matriz identidade das variáveis } \\
\text { (itens) do teste }\end{array}$ & Significativo para $\mathbf{p} \leq 0,05$ \\
\hline \multirow[t]{7}{*}{$\begin{array}{l}2^{a} \text { extração dos } \\
\text { fatores }\end{array}$} & \multirow[t]{2}{*}{ Método } & Fatorização do Eixo Principal & $\begin{array}{l}\text { Combinar fatores } \\
\text { considerar os erros }\end{array}$ \\
\hline & & Componentes principais & $\begin{array}{l}\text { Reunir itens com variância } \\
\text { afins }\end{array}$ \\
\hline & Comunalidades & $\begin{array}{l}\text { Indica o quanto de variância } \\
\text { comum há entre os itens }\end{array}$ & Acima de 0,4 \\
\hline & Variância acumulada & Nivel de explicação do teste & Acima de $50 \%$ \\
\hline & Variância do fator & Nivel de explicação do fator & Mínimo de 5\% \\
\hline & Regra de Kaiser & Indica a "força" do fator extraído & Acima de 1 \\
\hline & Scree Plot & Visualizar o ponto de inflexão & A curva acentuada \\
\hline \multirow[t]{2}{*}{$\begin{array}{l}3^{\text {a }} \text { rotação dos } \\
\text { fatores extraídos }\end{array}$} & Rotação & $\begin{array}{l}\text { Varimax, Quartimax, Equamax, } \\
\text { Oblimin, Promax. }\end{array}$ & $\begin{array}{l}\text { Depende do objetivo do } \\
\text { estudo e dos tipos de } \\
\text { medida dos itens }\end{array}$ \\
\hline & Cargas fatoriais & & Acima de 0,4 \\
\hline
\end{tabular}

Fonte: Pontes Júnior (2014, p. 58).

Inicialmente, a primeira etapa da AFE, como mostra a figura 1, aborda a adequação da amostra. Logo, observou-se que o teste Kaiser-Meyer-Olkin (KMO) é igual a 0,77; e o Bartlett's Test of Sphericity (BTS) é significativo ( $\mathrm{p}<0,001)$. Por outro lado, Field (2009) corrobora e transcende a concepção de Pontes Júnior (2014), destacando a existência de mais um indicador de qualidade para a amostra por item, isto é, a matriz anti-imagem que passou a variar com valores entre [0,65; 0,86], estando eles acima de 0,50 (FIELD, 2009), como retrata a tabela 1. Esses três testes estatísticos evidenciam que a amostra formada pelos 39 respondentes, tendo oito itens na escala de avaliação, está classificada em uma categoria boa e adequada para a realização da AFE (FIELD, 2009; PONTES JÚNIOR, 2014). 
Tabela 1 - Matriz Anti-Imagem para os oito itens

\begin{tabular}{|c|c|c|c|c|c|c|c|c|c|}
\hline \multicolumn{10}{|c|}{ Anti-Image Matrices } \\
\hline & & Q.1 & Q.2 & Q.3 & Q.4 & Q.5 & Q.6 & Q.7 & Q.8 \\
\hline \multirow{8}{*}{$\begin{array}{l}\text { Anti-Image } \\
\text { Correlation }\end{array}$} & Q.1 & $0,80^{\mathrm{a}}$ &,- 27 &,- 02 &,- 05 &,- 26 &, 10 &,- 28 &,- 07 \\
\hline & Q.2 &,- 27 & $0,80^{\mathrm{a}}$ &,- 20 &,- 02 &,- 05 &, 04 &, 11 & ,09 \\
\hline & Q.3 &,- 02 &,- 20 & $0,77^{\mathrm{a}}$ &,- 58 &,- 09 &,- 31 & ,06 &,- 06 \\
\hline & Q.4 &,- 05 &,- 02 &,- 58 & $0,74^{\mathrm{a}}$ &,- 39 &, 17 &, 04 &,- 19 \\
\hline & Q.5 &,- 26 &,- 05 &,- 09 &,- 39 & $0,86^{\mathrm{a}}$ &,- 02 &,- 08 & ,01 \\
\hline & Q.6 &, 10 &, 04 &,- 31 &, 17 &,- 02 & $0,65^{\mathrm{a}}$ &,- 48 &,- 27 \\
\hline & Q.7 &,- 28 &, 11 & ,06 & ,04 &,- 08 &,- 48 & $0,66^{\mathrm{a}}$ &,- 04 \\
\hline & Q.8 &,- 07 &, 09 &,- 06 &,- 19 & ,01 &,- 27 &,- 04 & $0,86^{\mathrm{a}}$ \\
\hline
\end{tabular}

a. Measures of Sampling Adequacy (MSA)

Fonte: Elaboração própria (2019) a partir do SPSS (20.0).

Em seguida, contemplou-se a segunda etapa da AFE, que aborda a extração dos fatores, como mostra a figura 1, ao adotar o método das Componentes Principais (CP). Desse modo, notou-se que as comunalidades, após a extração, passaram a variar entre [0,46;0,73], como mostra a tabela 2; o gráfico 7, a partir da interpretação do critério da raiz latente, informa a existência de dois fatores significativos para nossa escala de avaliação com oito itens.

Tabela 2 - Comunalidades dos oito itens

\begin{tabular}{l|l|l}
\hline \multicolumn{3}{l}{ Communalities } \\
\hline & Initial & Extraction \\
\hline $\mathrm{Q} .1$ & 1,00 & 0,46 \\
\hline $\mathrm{Q} .2$ & 1,00 & 0,51 \\
\hline $\mathrm{Q} .3$ & 1,00 & 0,72 \\
\hline $\mathrm{Q} .4$ & 1,00 & 0,75 \\
\hline $\mathrm{Q} .5$ & 1,00 & 0,67 \\
\hline $\mathrm{Q} .6$ & 1,00 & 0,73 \\
\hline $\mathrm{Q} .7$ & 1,00 & 0,66 \\
\hline Q.8 & 1,00 & 0,48 \\
\hline Extraction Method: Principal Component \\
Analysis.
\end{tabular}

Fonte: Elaboração própria (2019) a partir do SPSS (20.0). 


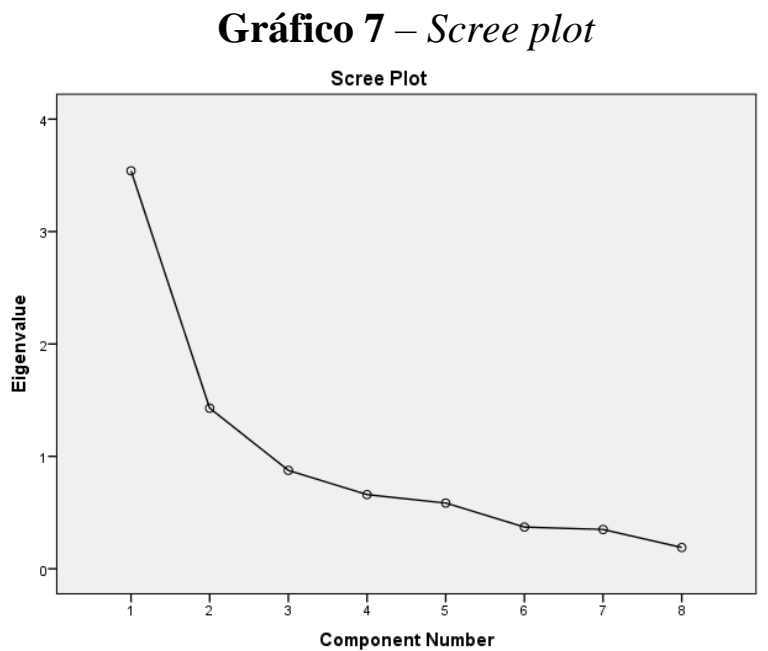

Fonte: Elaboração própria (2019) a partir do SPSS (20.0)

Posteriormente, por meio da AFE expressa através da variância total dos oito itens contidos no questionário semiestruturado, verificou-se, conforme a análise feita na tabela 3 a seguir, a variância total explicada acumulada de 62,1\% para dois fatores (Q1; Q2).

O fator denominado Q.1 contido no questionário semiestruturado vincula-se por meio da liderança estabelecida pelo compartilhamento das ações, visão, valores e ética atreladas aos discentes, docentes e gestores das instituições pesquisadas. Dessa forma, o respectivo fator contradiz o exposto por Paro (2016a, p. 122):

$\mathrm{Na}$ estrutura formal de nossa escola pública está quase totalmente ausente a previsão de relações humanas horizontais, de solidariedade e cooperação entre as pessoas, observando-se, em vez disso, a ocorrência de uma ordenação em que prevalecem relações hierárquicas de mando e submissão.

Assim, as decisões são partilhadas, verificando-se, pois, uma autonomia e colaboração entre os sujeitos que compõem a escola.

O fator denominado Q.2 relaciona-se aos planos de ação traçados pelo núcleo gestor e, dessa forma, para Lück (2013, p. 65):

[...] a preocupação com o monitoramento e a avaliação corresponde à dedicação ao alcance da efetividade das ações educacionais promovidas mediante ações observadas, analisadas e acompanhadas em relação ao atendimento das necessidades educacionais da comunidade escolar e os objetivos educacionais.

Portanto, os planos de ação constituem-se como elementos norteadores das ações que são desempenhadas na escola. 
Tabela 3 - Variância total explicada dos oito itens

\begin{tabular}{|c|c|c|c|c|c|c|c|c|c|}
\hline \multicolumn{10}{|c|}{ Total Variance Explained } \\
\hline \multirow{2}{*}{$\begin{array}{l}\text { Co } \\
\text { mpo } \\
\text { nent }\end{array}$} & \multicolumn{3}{|c|}{ Initial Eigenvalues } & \multicolumn{3}{|c|}{$\begin{array}{l}\text { Extraction Sums of Squared } \\
\text { Loadings }\end{array}$} & \multicolumn{3}{|c|}{$\begin{array}{l}\text { Rotation Sums of Squared } \\
\text { Loadings }\end{array}$} \\
\hline & Total & $\begin{array}{l}\% \text { of } \\
\text { Variance }\end{array}$ & $\begin{array}{l}\text { Cumulat } \\
\text { ive \% }\end{array}$ & Total & $\begin{array}{l}\text { \% of } \\
\text { Varianc } \\
e\end{array}$ & $\begin{array}{l}\text { Cumulati } \\
\text { ve } \%\end{array}$ & Total & $\begin{array}{l}\% \text { of } \\
\text { Variance }\end{array}$ & $\begin{array}{l}\text { Cumulati } \\
\text { ve } \%\end{array}$ \\
\hline 1 & 3,54 & 44,26 & 44,26 & 3,54 & 44,26 & 44,26 & 2,93 & 36,58 & 36,58 \\
\hline 2 & 1,43 & 17,86 & 62,12 & 1,43 & 17,86 & 62,12 & 2,04 & 25,54 & 62,12 \\
\hline 3 & ,88 & 10,94 & 73,07 & & & & & & \\
\hline 4 & ,66 & 8,25 & 81,31 & & & & & & \\
\hline 5 &, 58 & 7,31 & 88,62 & & & & & & \\
\hline 6 & ,37 & 4,64 & 93,26 & & & & & & \\
\hline 7 &, 35 & 4,37 & 97,63 & & & & & & \\
\hline 8 & , 19 & 2,37 & 100,0 & & & & & & \\
\hline
\end{tabular}

Fonte: Elaboração própria (2019) a partir do SPSS (20.0).

Abordou-se a terceira etapa da AFE, destacando a rotação dos fatores extraídos, como mostra a figura 1. Então, optou-se pela rotação Varimax. Tal ação produziu três interações de rotação convergente. Nesse sentido, pode-se perceber as seguintes características de cada um dos dois fatores obtidos, tais como:

(a) O fator 1 apresenta um compartilhamento de cargas fatoriais nos itens Q1, Q2, Q3, Q4 e Q5, como mostra a quadro 2. Além disso, percebemos que tanto a consistência/formulação do fator 1 apresenta qualidade boa, uma vez que o alfa de Cronbach $(\alpha)$ é igual a $0,81 \approx 0,8$ e as Corrected Item-Total Correlation passaram a variar entre [0,45; 0,72], como retrata a quadro 3. Desse modo, iremos nomeá-lo de ações do núcleo gestor, uma vez que esses cinco itens abordam em suas semânticas a operacionalização crítica/reflexiva do núcleo gestor quanto à asseguração da liderança, à implementação, à parceria, aos diálogos, à proatividade, à coletividade e ao respeito mútuo entre a triagem gestor-educador-professor na instituição de ensino.

(a) O fator 2 apresenta um compartilhamento de cargas fatoriais nos itens Q6, Q7 e Q8, como mostra a quadro 2. Ademais, percebemos que tanto a consistência/formulação do fator 2 apresenta qualidade boa, uma vez que o alfa de Cronbach $(\alpha)$ é igual a $0,69 \approx 0,7$ e as Corrected Item-Total Correlation passaram a variar entre $[0,61 ; 0,85]$, como retrata a quadro 3 . Nesse sentido, iremos nomeá-lo de prática mútua institucional do público escolar, já que esses três itens destacaram em suas afirmativas a prática existente na formação atenta e continuada, nas estratégias integradas de comunicação e nos envolvimentos da gestão, comunidade, professores e discentes. 
Quadro 2 - Matriz rotacional dos oito itens

\begin{tabular}{|l|c|c|}
\hline \multicolumn{2}{|l|}{ Rotated Component Matrix ${ }^{a}$} & \multicolumn{2}{|c|}{ Component } \\
\cline { 2 - 3 } & Fator 1 & Fator 2 \\
\hline $\begin{array}{l}\text { Q.4 O núcleo gestor verifica as demandas a partir das relações } \\
\text { vivenciadas na escola, promovendo resoluções por meio de ações } \\
\text { proativas. }\end{array}$ & 0,84 & \\
\hline $\begin{array}{l}\text { Q.3 O núcleo gestor desenvolve parcerias e diálogos entre professores, } \\
\text { alunos e comunidade escolar. }\end{array}$ & 0,78 & \\
\hline $\begin{array}{l}\text { Q.5 A equipe gestora auxilia no trabalho coletivo, na disciplina e no } \\
\text { estabelecimento de respeito entre os sujeitos que integram a escola. }\end{array}$ & 0,78 & \\
\hline $\begin{array}{l}\text { Q.2 O gestor compromete-se em assegurar a implementação dos planos } \\
\text { de ação através dos seus respectivos programas de ação. }\end{array}$ & 0,69 & \\
\hline $\begin{array}{l}\text { Q.1 No tocante à liderança: gestor e educadores desenvolvem visão, } \\
\text { missão, valores e ética relacionados aos educandos }\end{array}$ & 0,63 & \\
\hline $\begin{array}{l}\text { Q.6 A formação ofertada aos docentes constitui-se de forma atenta e } \\
\text { continuada. }\end{array}$ & 0,85 \\
\hline $\begin{array}{l}\text { Q.7 Na dinâmica apresentada na escola, observa-se o envolvimento } \\
\text { entre o núcleo gestor e a comunidade escolar }\end{array}$ & 0,81 \\
\hline $\begin{array}{l}\text { Q.8 As estratégias de comunicação adotadas na escola são eficazes para } \\
\text { a integração entre a gestão, professores, discentes e comunidade escolar }\end{array}$ & & 0,61 \\
\hline $\begin{array}{l}\text { Extraction Method: Principal Component Analysis. } \\
\text { Rotation Method: Varimax with Kaiser Normalization. }\end{array}$ & \\
\hline a. Rotation converged in 3 iterations. & \\
\hline
\end{tabular}

Fonte: Elaboração própria (2019) a partir do SPSS (20.0).

Assim, a AFE formada pelos oito itens compreende uma variância total explicada de $62,1 \%$ a partir da construção de dois fatores significativos, são eles: o fator 1, que trata sobre as ações do núcleo gestor, e o fator 2, que aborda a prática mútua institucional, sendo que ambos apresentam boa qualidade de composição/formulação. Em conformidade, Paro (2012, p. 25) explica que “[...] essa transcendência se dá à medida que ele busca realizar, por meio da ação racional, os objetivos a que propõe". Dessa forma, a gestão dos elementos que norteiam a prática educativa sedimenta-se como componente das práticas e das ações desenvolvidas na escola. 
Quadro 3 - Qualidade dos dois fatores rotacionais pelo método Varimax

\begin{tabular}{|c|c|c|c|}
\hline & $\begin{array}{l}\text { Cronbach's } \\
\text { Alpha }\end{array}$ & Item-Total Statistics & $\begin{array}{l}\text { Corrected } \\
\text { Item-Total } \\
\text { Correlation }\end{array}$ \\
\hline \multirow{5}{*}{ Fator 1} & \multirow{5}{*}{0,81} & $\begin{array}{l}\text { Q.1 No tocante à liderança: gestor e educadores } \\
\text { desenvolvem visão, missão, valores e ética } \\
\text { relacionados aos educandos. }\end{array}$ & 0,54 \\
\hline & & $\begin{array}{l}\text { Q.2 O gestor compromete-se em assegurar a } \\
\text { implementação dos planos de ação através dos seus } \\
\text { respectivos programas de ação. }\end{array}$ & 0,45 \\
\hline & & $\begin{array}{l}\text { Q.3 O núcleo gestor desenvolve parcerias e } \\
\text { diálogos entre professores, alunos e comunidade } \\
\text { escolar. }\end{array}$ & 0,69 \\
\hline & & $\begin{array}{l}\text { Q.4 O núcleo gestor verifica as demandas a partir } \\
\text { das relações vivenciadas na escola, promovendo } \\
\text { resoluçôes por meio de ações proativas. }\end{array}$ & 0,72 \\
\hline & & $\begin{array}{l}\text { Q.5 A equipe gestora auxilia no trabalho coletivo, } \\
\text { na disciplina e no estabelecimento de respeito entre } \\
\text { os sujeitos que integram a escola. }\end{array}$ & 0,67 \\
\hline \multirow{3}{*}{ Fator 2} & \multirow{3}{*}{0,7} & $\begin{array}{l}\text { Q.6 A formação ofertada aos docentes constitui-se } \\
\text { de forma atenta e continuada. }\end{array}$ & 0,61 \\
\hline & & $\begin{array}{l}\text { Q.7 Na dinâmica apresentada na escola, observa-se } \\
\text { o envolvimento entre o núcleo gestor e a } \\
\text { comunidade escolar. }\end{array}$ & 0,51 \\
\hline & & $\begin{array}{l}\text { Q.8 As estratégias de comunicação adotadas na } \\
\text { escola são eficazes para a integração entre a gestão, } \\
\text { professores, discentes e comunidade escolar. }\end{array}$ & 0,42 \\
\hline
\end{tabular}

Fonte: Elaboração própria (2019) a partir do SPSS (20.0).

Além disso, resolveu-se avaliar o nível de concordância/discordância dos itens organizados em categorias/fatores, conforme as respostas dos $(n=39)$ professores respondentes. Para o fator 1, que aborda as ações do núcleo gestor, temos os itens: Q1, Q2, Q3, Q4 e Q5. Logo, observamos que a maioria dos sujeitos está mais concordando [parcialmente; plenamente] do que discordando em cada uma dessas sentenças apresentadas, como retrata a quadro 4.

Diante disso, as condições apresentadas devem estar intrinsecamente relacionadas ao modo determinante de trabalho do núcleo gestor perante os objetos, pois, de acordo com Paro (2016b, p. 2), “[...] toma-se a escola onde se busca, de forma sistemática e organizada, a apropriação do saber”. Assim, por meio de um trabalho coeso, as instituições poderão ter o alcance de suas metas e objetivos educacionais. 
Quadro 4 - Nível de concordância/discordância fator 1

\begin{tabular}{|c|c|c|c|}
\hline Itens & Variação escala Likert & $\mathbf{F}$ & $\%$ \\
\hline \multirow{4}{*}{$\begin{array}{l}\text { Q.1 No tocante à liderança: gestor e } \\
\text { educadores desenvolvem visão, missão, } \\
\text { valores e ética relacionados aos educandos. }\end{array}$} & 1 - Discordo totalmente & 1 & 2,6 \\
\hline & 2 - Discordo parcialmente & 2 & 5,1 \\
\hline & 3 - Concordo parcialmente & 9 & 23,1 \\
\hline & 4 - Concordo plenamente & 27 & 69,2 \\
\hline \multirow{4}{*}{$\begin{array}{l}\text { Q.2 O gestor compromete-se em assegurar a } \\
\text { implementação dos planos de ação através } \\
\text { dos seus respectivos programas de ação. }\end{array}$} & 0 - Não sei responder & 1 & 2,6 \\
\hline & 1 - Discordo totalmente & 1 & 2,6 \\
\hline & 3 - Concordo parcialmente & 4 & 10,2 \\
\hline & 4 - Concordo plenamente & 33 & 84,6 \\
\hline \multirow{3}{*}{$\begin{array}{l}\text { Q.3 O núcleo gestor desenvolve parcerias e } \\
\text { diálogos entre professores, alunos e } \\
\text { comunidade escolar. }\end{array}$} & 1 - Discordo totalmente & 1 & 2,6 \\
\hline & 3 - Concordo parcialmente & 12 & 30,7 \\
\hline & 4 - Concordo plenamente & 26 & 66,7 \\
\hline \multirow{3}{*}{$\begin{array}{l}\text { Q.4 O núcleo gestor verifica as demandas a } \\
\text { partir das relações vivenciadas na escola, } \\
\text { promovendo resoluções por meio de ações } \\
\text { proativas. }\end{array}$} & 1 - Discordo totalmente & 1 & 2,6 \\
\hline & 3 - Concordo parcialmente & 11 & 28,2 \\
\hline & 4 - Concordo plenamente & 27 & 69,2 \\
\hline \multirow{4}{*}{$\begin{array}{l}\text { Q.5 A equipe gestora auxilia no trabalho } \\
\text { coletivo, na disciplina e no estabelecimento } \\
\text { de respeito entre os sujeitos que integram a } \\
\text { escola. }\end{array}$} & 1 - Discordo totalmente & 1 & 2,6 \\
\hline & 2 - Discordo parcialmente & 2 & 5,1 \\
\hline & 3 - Concordo parcialmente & 6 & 15,4 \\
\hline & 4 - Concordo plenamente & 30 & 76,9 \\
\hline
\end{tabular}

Fonte: Elaboração própria (2019) a partir do SPSS (20.0).

No que diz respeito ao fator 2, que aponta a prática mútua institucional, temos os itens: Q6, Q7 e Q8. Então, notamos que a maioria das pessoas está mais concordando [parcialmente; plenamente] do que discordando em cada uma dessas sentenças apresentadas, como retrata o quadro 5.

Quadro 5 - Nível de concordância/discordância fator 2

\begin{tabular}{|l|l|l|l|}
\hline Itens & Variação escala Likert & F & $\mathbf{\%}$ \\
\hline \multirow{4}{*}{$\begin{array}{l}\text { Q.6 A formação ofertada aos docentes } \\
\text { constitui-se de forma atenta e continuada. }\end{array}$} & 0 - Não sei responder & 1 & 2,6 \\
\cline { 2 - 4 } & 1 - Discordo totalmente & 1 & 2,6 \\
\cline { 2 - 4 } & 2 - Discordo parcialmente & 9 & 23,0 \\
\cline { 2 - 4 } & 3 - Concordo parcialmente & 17 & 43,6 \\
\cline { 2 - 4 } & 4 - Concordo plenamente & 11 & 28,2 \\
\hline \multirow{2}{*}{$\begin{array}{l}\text { Q.7 Na dinâmica apresentada na escola, } \\
\text { observa-se o envolvimento entre o núcleo } \\
\text { gestor e a comunidade escolar. }\end{array}$} & 0 - Não sei responder & 1 & 2,6 \\
\cline { 2 - 4 } & 2 - Discordo parcialmente & 4 & 10,2 \\
\cline { 2 - 4 } $\begin{array}{l}\text { Q.8 As estratégias de comunição adotadas } \\
\text { na escola são eficazes para a integração } \\
\text { entre a gestão, professores, discentes e } \\
\text { comunidade escolar. }\end{array}$ & 4 - Concordo parcialmente & 12 & 30,8 \\
\cline { 2 - 4 } & 0 - Não sei responder & 1 & 56,4 \\
\cline { 2 - 4 } & 1 - Discordo totalmente & 1 & 2,6 \\
\cline { 2 - 4 } & 3 - Discordo parcialmente & 3 & 7,6 \\
\cline { 2 - 5 } & 4 - Concordo parcialmente & 18 & 46,2 \\
\hline
\end{tabular}

Fonte: Elaboração própria (2019) a partir do SPSS (20.0). 
Dessa forma, a seguir, serão apresentadas as considerações finais acerca do estudo, salientando as contribuições advindas por meio da temática e também das demandas vivenciadas no contexto dos sujeitos respondentes, os professores, e o modo como as avaliações externas direcionam o modelo de avaliação e de gestão, inserindo-o basilar para as práticas e ações visualizadas nas escolas estaduais inseridas na modalidade de Educação Profissional.

\section{Considerações finais}

A partir da avaliação da gestão por meio da análise de $(n=39)$ professores que integram a rede de escolas estaduais situadas na modalidade de educação profissional, observou-se que a gestão e o nivelamento das práticas institucionais configuram-se como elementos importantes para a proposição de práticas exitosas.

O diálogo e o regime de parceria são observados na dinâmica escolar, conforme a análise realizada. As categorias geradas por meio dos indicadores vinculados à análise fatorial denotam as ações do núcleo gestor, relacionando-as enquanto prática institucional significativa por meio da percepção dos sujeitos respondentes.

As categorias presentes no instrumental condensam de forma satisfatória, as diretrizes e as especificidades vinculadas a essas instituições. Dessa forma, cabe a ampliação do recorte da respectiva pesquisa, com o objetivo de ocasionar ações e melhoria nas práticas de gestão e no entendimento da avaliação enquanto acompanhamento dessas ações junto às Escolas Estaduais de Educação Profissional localizadas no município de Fortaleza, Ceará.

AGRADECIMENTOS: Coordenação de Aperfeiçoamento de Pessoal de Nível Superior (Capes).

\section{REFERÊNCIAS}

BAUER, A. Avaliação de impacto no Brasil: é possível mensurar impacto de programas de formação docente? Estudos em Avaliação Educacional, v. 21, n. 46, p. 229-252, 2010.

BRASIL. Lei n. 13.005, de 25 junho de 2014. Aprova o Plano Nacional de Educação - PNE e dá outras providências. Diário Oficial [da] República Federativa do Brasil, Poder Executivo, Brasília, DF, 2014.

BRASIL. Lei n. 9.394, de 20 de dezembro de 1996. Estabelece as diretrizes e bases da educação nacional. Diário Oficial [da] República Federativa do Brasil, Poder Executivo, Brasília, DF, 2017. 
BRASIL. Decreto n. 9.432, de 29 de junho de 2018. Regulamenta a política nacional de avaliação e exames da educação básica. Diário Oficial [da] República Federativa do Brasil, Poder Executivo, Brasília, DF, 2018.

BONAMINO, A.; FRANCO, C. Avaliação e políticas educacionais: o processo de institucionalização do SAEB. Caderno de Pesquisa, n. 108, p. 101-132, 1999.

BRUYNE, P.; HERMAN, J.; SCHOUTHEETE, M. Dinâmica da pesquisa em ciências sociais: os polos da prática metodológica. Trad. Ruth Joffily. Rio de Janeiro: Francisco Alves, 1977.

CARNOY, M. O estruturalismo e o Estado: Althusser e Poulantzas. In: CARNOY, M. (Org.). Estado e teoria política. Campinas: Papirus, 1987, p. 119-164.

CERQUEIRA, W. Taylorismo e fordismo. Brasil Escola. 2018. Disponível em: https://brasilescola.uol.com.br/geografia/taylorismo-fordismo.htm. Acesso: 17 set. 2019.

DUARTE, N.; OLIVEIRA, B. Socialização do saber escolar. São Paulo: Cortez, 1987.

ENGELS, F. O papel do trabalho na transformação do macaco em homem. 1876. Disponível em: http://www.marxists.org/portugues/marx/1876/mes/macaco.htm. Acesso em: 24 jul. 2019.

ENGUITA, M. F. A face oculta da escola: educação e trabalho no capitalismo. Porto Alegre: Artes Médicas. 1989.

FIELD, A. Discovering statistics using SPSS. 3. ed. London: Sage, 2009.

KUENZER, A. Z. Ensino de $\mathbf{2}^{\mathbf{0}}$ grau: o trabalho como princípio educativo. São Paulo: Cortez, 1992.

LÜCK, H. Avaliação e monitoramento do trabalho educacional. Petrópolis: Vozes, 2013.

MARCONI, M.; LAKATOS, E. Fundamentos da metodologia científica. São Paulo: Atlas, 2015.

MINAYO, M.; DESLANDES, S.; CRUZ NETO, O.; GOMES, R. Pesquisa social: teoria, método e criatividade. Petrópolis: Vozes, 1994.

PARO, V. Administração escolar: introdução crítica. São Paulo: Cortez, 2012.

PARO, V. Crítica da estrutura da escola. São Paulo: Cortez, 2016a.

PARO, V. Gestão democrática da escola. São Paulo: Cortez, $2016 b$.

PINTO, R.; VIANA, M. As avaliações externas e a escola: possibilidades e desafios para a sala de aula. 2019. Disponível em: as-avaliaexternas-e-a-escola-possibilidades-e-desafiospara-a-sala-de-aula.pdf. Acesso em: 12 jul. 2019. 
PONTES JÚNIOR, J. Matriz ACEF9: matriz de referência para avaliação cognitiva em larga escala dos conteúdos da educação física no ensino fundamental ( $9^{\circ}$ ano). 2014. 128f. Tese (Doutorado em Educação) - Universidade Federal do Ceará, Programa de Pós-graduação em Educação Brasileira, Fortaleza (CE), 2014.

SANTOS, A.; GIMENES, O.; MARIANO, S. Avaliações externas e seus impactos nas práticas pedagógicas: percepções e visões preliminares. Revista Encontro de Pesquisa em Educação, v. 1, n. 1, p. 38-50, 2013.

\section{SEDUC. Secretaria da Educação. Escolas Estaduais de Educação Profissional (EEEP).} 2019. Disponível em:

educacaoprofissional.seduc.ce.gov.br/index.php?option=com_content\&view=article\&id=3\&It emid=103. Acesso em: 12 jul. 2019.

SEVERINO, A. Metodologia do trabalho científico. 24. ed. São Paulo: Cortez. 2016.

SOUZA, L. A. S.; OKÇANA, B. A formação por base em competências na educação profissional frente às novas tecnologias. In: Jornada de Didática e do I Seminário de Pesquisa do Cemad. Londrina, Paraná. Anais [...]. Londrina, Paraná, Brasil, 2013.

TITTON, M. O princípio educativo do trabalho e o trabalho enquanto princípio educativo: ampliando o debate com os movimentos de luta social. In: Reunião Anual da Anped, 31., 2008. Disponível em: anped.org.br/biblioteca/item/o-principio-educativo-do-trabalho-e-otrabalho-enquanto-principio-educativo. Acesso em: 12 jul. 2019.

VIEIRA, S. L. Estrutura e funcionamento da educação básica. 2. ed. Fortaleza: UECE. 2015.

\section{Como referenciar este artigo}

LIMA, Marcos Antonio Martins; SILVA, Denize de Melo; OLIVEIRA, Maria Lucijane Gomes de; SILVA, Jaderson Cavalcante da. Avaliação da gestão no ensino técnico profissional: implicações da reforma do ensino médio. Revista on line de Política e Gestão Educacional, Araraquara, v. 24, n. 2, p. 347-371, maio/ago., 2020. e-ISSN: 1519-9029. DOI: https://doi.org/10.22633/rpge.v24i2.13305

Submetido em: 10/01/2020

Revisões requeridas: $20 / 02 / 2020$

Aprovado em: 24/02/2020

Publicado em: 09/04/2020 